\title{
Effects of a Water-Soluble Cinnamon Extract on Body Composition and Features of the Metabolic Syndrome in Pre-Diabetic Men and Women
}

\author{
Tim N. Ziegenfuss ${ }^{1}$, Jennifer E. Hofheins ${ }^{1}$, Ronald W. Mendel ${ }^{1}$, \\ Jamie Landis ${ }^{2}$, Richard A. Anderson ${ }^{3}$ \\ Ohio Research Group, Wadsworth Medical Center, Wadsworth, $\mathrm{OH}^{1}$; Lakeland Community College, Dept of \\ Biology, Kirtland, $\mathrm{OH}^{2}$; Nutrients Requirements and Functions Laboratory, Beltsville Human Nutrition \\ Research Center, Beltsville, MD³ . Address correspondence to tim@ohioresearchgroup.com
}

Received August 7, 2006/Accepted December 28, 2006

\begin{abstract}
Purpose: The purpose of this study was to determine the effects of supplementation with a water-soluble cinnamon extract (Cinnulin $\mathrm{PF}{ }^{\circledR}$ ) on body composition and features of the metabolic syndrome. Methods: Twenty-two subjects with prediabetes and the metabolic syndrome (mean \pm SD: age, BMI, systolic blood pressure [SBP], fasting blood glucose [FBG]: $46.0 \pm 9.7 \mathrm{y} ; 33.2 \pm 9.3 \mathrm{~kg} / \mathrm{m}^{2} ; 133 \pm 17 \mathrm{~mm} \mathrm{Hg} ; 114.3 \pm 11.6$ $\mathrm{mg} / \mathrm{dL})$ were randomly assigned to supplement their diet with either Cinnulin PF ${ }^{\circledR}(500 \mathrm{mg} / \mathrm{d})$ or a placebo for 12-weeks. Main outcome measures were changes in FBG, SBP, and body composition measured after 12-weeks of supplementation. The primary statistical analyses consisted of two factor (group x time), repeated-measures ANOVA for between group differences over time. In all analyses, an intent-to-treat approach was used and significance was accepted at $\mathrm{P}<0.05$. Results: Subjects in the Cinnulin $\mathrm{PF}{ }^{\circledR}$ group had significant decreases in FBG (-8.4\%: $116.3 \pm 12.8 \mathrm{mg} / \mathrm{dL}$ [pre] to $106.5 \pm 20.1 \mathrm{mg} / \mathrm{dL}$ [post], $\mathrm{p}<0.01), \mathrm{SBP}(-3.8 \%: 133 \pm 14 \mathrm{~mm} \mathrm{Hg}$ [pre] to $128 \pm 18 \mathrm{~mm} \mathrm{Hg}$ [post], $\mathrm{p}<0.001)$, and increases in lean mass $(+1.1 \%: 53.7 \pm 11.8 \mathrm{~kg}$ [pre] to $54.3 \pm$ $11.8 \mathrm{~kg}$ [post], $\mathrm{p}<0.002)$ compared with the placebo group. Additionally, within-group analyses uncovered small, but statistically significant decreases in body fat $(-0.7 \%: 37.9 \pm 9.2 \%$ [pre] to $37.2 \pm 8.9 \%$ [post], $\mathrm{p}<0.02)$ in the Cinnulin PF® group. No significant changes in clinical blood chemistries were observed between groups over time. Conclusions: These data support the efficacy of Cinnulin $\mathrm{PF}{ }^{\circledR}$ supplementation on reducing FBG and SBP, and improving body composition in men and women with the metabolic syndrome and suggest that this naturally-occurring spice can reduce risk factors associated with diabetes and cardiovascular diseases. Journal of the International Society of Sports Nutrition. 3(2): 45 - 53, 2006.
\end{abstract}

Key Words: prediabetes, glucose, body fat, insulin, systolic blood pressure, dyslipidemia

\section{INTRODUCTION}

A number of spices and herbs have a long history of traditional use in treating elevated blood sugar levels 1 . One such compound that has recently been the subject of intense research is cinnamon, a compound granted GRAS (Generally Recognized As Safe) status by the United States Food and Drug Administration. The beneficial effects of cinnamon on glucose control appear to be in part due to doublylinked polyphenol type-A compounds ${ }^{2}$. Over the past two decades, in vitro and in vivo data have been accumulating which support the role of cinnamon on glycemic control. For example, Jarvill-Taylor et al. ${ }^{3}$ reported that cinnamon stimulated glucose uptake, glycogen synthesis, and activated glycogen synthase in 3T3-L1 adipocytes. In rats, cinnamon enhanced glucose uptake by enhancing insulin-stimulated tyrosine phosphorylation of insulin receptor- $\beta$, insulin receptor substrate-1, and phosphatidylinositol 3-kinase in a dose-dependent fashion ${ }^{4,5}$. To date, human studies demonstrating beneficial effects of cinnamon supplementation on glucose regulation have studied subjects with type II diabetes ${ }^{6,7}$. In a dose-response study, Khan et al. ${ }^{6}$ reported that 40days of supplementation with 1,3 , or 6 grams of whole cinnamon per day resulted in dose-dependent decreases in fasting blood glucose (FBG), and 
improvements in blood lipid profiles, in subjects with poorly controlled diabetes and dyslipidemia. More recently, Mang et al. ${ }^{7}$ reported a $10.3 \%$ decrease in FBG after four months of supplementation with a purified aqueous cinnamon extract. Thus, the effects of cinnamon and cinnamon extract on improving insulin signaling and glucose regulation in type II diabetics appear promising.

Several studies have linked diabetes to obesityinduced insulin resistance ${ }^{8}$. In this regard, an estimated 41 million people in the U.S. have prediabetes, a condition of elevated fasting blood sugar that is strongly associated with hyperlipidemias and cardiovascular disease ${ }^{9}$. When considered collectively, elevated blood sugar, hyperlipidemia, hypertension, and obesity constitute a potentially dangerous physiological condition known as "Syndrome X" or the Metabolic Syndrome. The National Cholesterol Education Program has established the current criteria for the metabolic syndrome as $\geq$ three of the following: 1) waist circumference $>102 \mathrm{~cm}$ (40 inches) for men or $>88$ $\mathrm{cm}$ (35 inches) for women; 2) a fasting total serum triacylglycerol concentration of $>1.7 \mathrm{mmol} / \mathrm{L}(150$ $\mathrm{mg} / \mathrm{dL}) ; 3$ ) a fasting HDL cholesterol concentration $<$ $1.0 \mathrm{mmol} / \mathrm{L}(40 \mathrm{mg} / \mathrm{dL})$ for men or $<1.2 \mathrm{mmol} / \mathrm{L}(50$ $\mathrm{mg} / \mathrm{dL}$ ) for women; 4) a fasting glucose $>6.1$ $\mathrm{mmol} / \mathrm{L}(110 \mathrm{mg} / \mathrm{dL})$; or blood pressure $>130 \mathrm{~mm}$ $\mathrm{Hg}$ (systolic) and/or $85 \mathrm{~mm} \mathrm{Hg}$ (diastolic) and/or the use of antihypertensive medication ${ }^{10}$. In addition to the positive effects of cinnamon on glucose regulation, there are data which support the beneficial effects of cinnamon on blood pressure ${ }^{11}$ and hyperlipidemias ${ }^{6}$. Though limited, the existing evidence suggests a potential role for cinnamon as a positive influence on several features of the metabolic syndrome.

The purpose of this placebo-controlled, double-blind study was to determine the effects of supplementation with a specific water-soluble cinnamon extract (Cinnulin PF®) on FBG and body composition in prediabetic men and women with features of the metabolic syndrome. In addition, to assess the safety profile of this compound we measured changes in standard markers of health (e.g., resting heart rate and blood pressure) and clinical chemistry panels of serum and plasma. Several markers of plasma antioxidant status as well as long-term glucose control and insulin sensitivity were also measured, and will be addressed in a separate manuscript (in preparation).

\section{RESEARCH DESIGN AND METHODS}

Experimental approach. This study was a randomized, placebo-controlled, double-blind clinical trial with two parallel groups. Serum chemistry, body weight, and body composition were measured at baseline and at the end of the 12-week supplementation period. Subjects also completed 3day food records and had measurements of their systolic and diastolic blood pressures during pre (week 0), mid (week 6), and post (week 12) testing. Figure 1 presents the flow of participants through the study.

Subjects. Subjects were recruited from northeastern Ohio, a typical suburban region, by word of mouth and posted announcements. Thirty potential participants aged 30-60 years were interviewed by telephone. Of these, 22 were invited for a preliminary screening consisting of height, weight, blood pressure, and a fasting blood sample. Subjects were required to have $\mathrm{FBG}$ between $100 \mathrm{mg} / \mathrm{dL}$ (5.6 $\mathrm{mmol} / \mathrm{L})$ and $125 \mathrm{mg} / \mathrm{dL}(6.9 \mathrm{mmol} / \mathrm{L})$, have normal values for liver and kidney function tests, and be willing to maintain their usual dietary and physical activity habits. Subjects were excluded from the study if they had a body mass index (BMI) $>40$ $\mathrm{kg} / \mathrm{m}^{2}$, thyroid disease, hypogonadism, a history of musculoskeletal, autoimmune, or neurologic disease, or if they were currently taking thyroid, hyperlipidemic, hypoglycemic, anti-hypertensive, or anti-coagulant medications. Prior to obtaining written informed consent from each subject, an institutional review board (IntegReview Inc, Austin, TX) approved the experimental protocol. All procedures in the study were in accord with ethical standards set forth in the Helsinki Declaration of 1975, as revised in 1983 .

Supplementation. After matching for age, FBG, SBP, and habitual physical activity levels, subjects were randomly assigned to a Cinnulin PF ${ }^{\circledR}(n=12)$ or placebo $(n=10)$ group. Each subject was instructed to take two capsules $(250 \mathrm{mg})$ of their respective supplement twice per day (with breakfast and dinner). According to the manufacturer, $500 \mathrm{mg}$ of Cinnulin $\mathrm{PF}{ }^{\circledR}$ is equivalent to approximately $10 \mathrm{~g}$ of whole cinnamon powder (i.e., 20:1 extract), and contains at least $1 \%$ doubly-linked polyphenol typeA polymers (considered to be the bioactive component). Supplements were prepared in a 2-piece hard shell capsule form and packaged in coded generic containers for double-blind administration by Integrity Nutraceuticals International (Sarasota, FL). Medical monitoring and compliance to the 


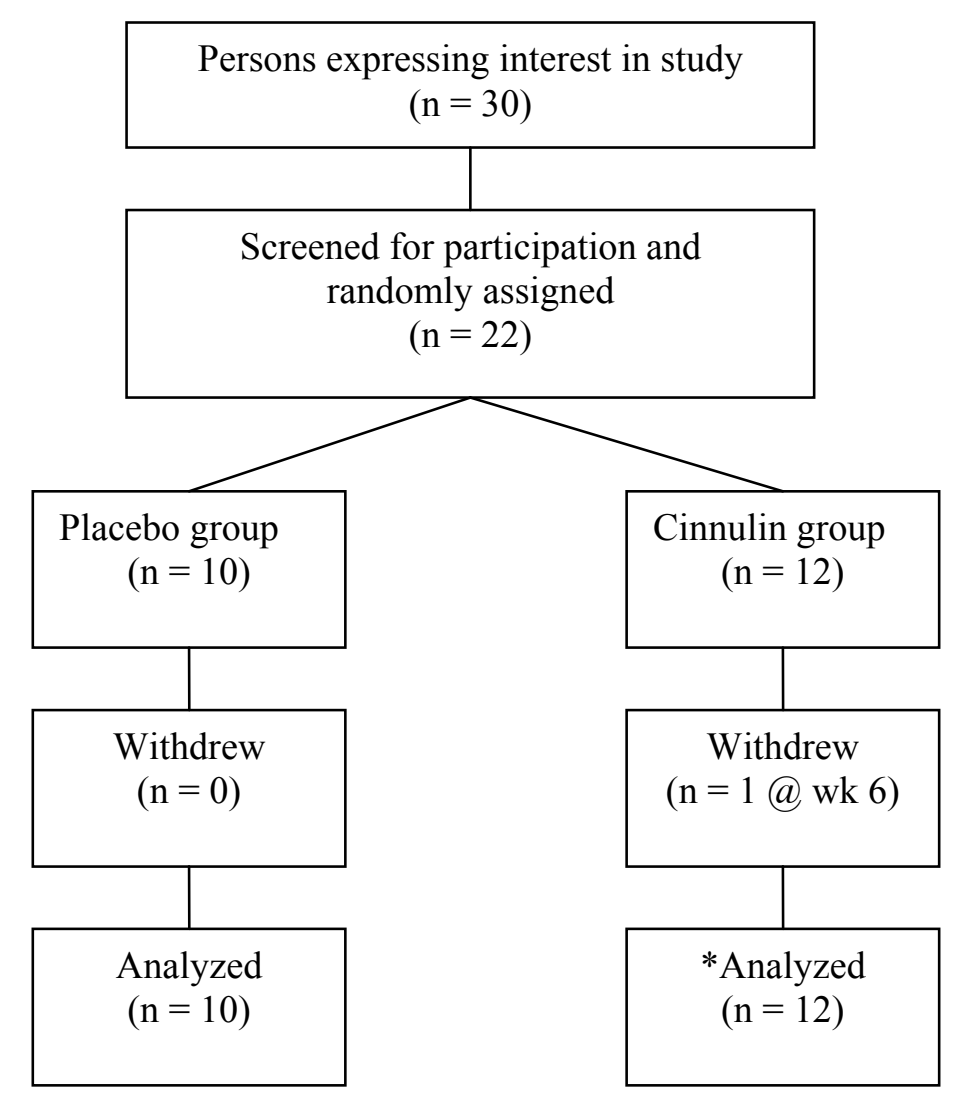

Figure 1. Study Flow Chart. *One subject in the Cinnulin group withdrew at week 6 due to pregnancy. For this subject, we imputed her remaining data using the last-observation-carried-forward method (i.e., week 0 values were used at week 6 and week 12).

supplementation protocol was supervised by a research technician who contacted the subjects on a weekly basis. Each subject was required to return the original bottle of their respective supplement for capsule counts during mid (week 6) and post (week 12) testing.

Heart rate and blood pressure. All subjects reported to the laboratory after a 12 -hour fast and at least 48hours after participating in intense physical activity. Following ten minutes of seated rest, subjects' heart rate and blood pressure were determined by palpation of the radial artery and aneroid sphygmomanometry, respectively. The same technician performed all measurements using standard procedures.

Blood collection and analyses. Immediately following blood pressure readings, approximately $20 \mathrm{~mL}$ of blood was drawn with stasis via venipuncture of an antecubital vein. All blood samples were taken in the morning at approximately the same time of day to minimize diurnal variation, and subjects used their baseline diet records to standardize their final (evening) meal before mid (week 6) and post (week 12) testing.

Blood samples were harvested into tubes with and without EDTA, centrifuged (Drucker Model 614, Philipsburg, PA) at room temperature for 15 minutes at $1200 \times \mathrm{g}$ to obtain plasma and serum, and immediately placed into two aliquots. One aliquot was immediately analyzed for a 21 -item clinical chemistry profile (Hitachi D2400, Roche Diagnostics, Germany) by a certified clinical laboratory (Laboratory Corporation of America, Dublin, $\mathrm{OH})$. This profile consisted of a comprehensive metabolic panel (glucose, BUN, creatinine, sodium, potassium, chloride, carbon dioxide, calcium, total protein, albumin, globulin, total bilirubin, alkaline phosphatase, 
AST [SGOT], and ALT [SGPT]) as well as a lipid profile (total cholesterol, HDL-C, LDL-C, VLDL-C, triacylglycerol).

Body composition. Body weight was measured using a calibrated digital $A \& D^{\mathrm{TM}}$ Medical Scale (Model UC-300, Milpitas, CA), standing height was measured using a wall-mounted stadiometer (Seca Model 216, Hanover, MD) and body composition was measured with dual-energy x-ray absorptiometry (GE Lunar DPX Pro, Madison, WI). All dual-energy $\mathrm{x}$-ray absorptiometry (DEXA) scans were performed by the same technician and analyzed according to software (enCORE version 7.53.002, 2003) provided by the manufacturer. Briefly, subjects were positioned in the scanner according to standard procedures and remained motionless for approximately 15 minutes during scanning. DEXA segments for the arms, legs, and trunk were subsequently obtained using standard anatomical landmarks. Using a three-compartment model, DEXA calculates fat mass, lean mass, and bone mass. Percent fat was calculated by dividing fat mass by the total scanned mass. Quality control calibration procedures were performed prior to all scans using a calibration block provided by the manufacturer. Prior to this study, we determined test-retest reliability for repeated measurements of lean mass, bone mineral content, and fat mass with this DEXA via intra-class correlation coefficients. All values were $>0.98$.

Diet and physical activity. As mentioned previously, this study used a free-living design where subjects were advised to maintain their normal diet during the study. To verify this, subjects completed 3-d food records (which included two weekdays and one weekend day) during baseline testing, week 6 , and week 12. All food records were analyzed by a licensed, registered dietitian using commercially available software (NutriBase IV Clinical Edition, AZ). To enhance accuracy of the food records, all subjects received instruction during baseline testing on how to accurately estimate portion sizes. This counseling was reinforced during each visit to the laboratory. No dietary supplements were allowed with the exception of standard strength multivitamins. Subjects were also advised to maintain their current level of habitual physical activity throughout the study. Physical activity levels were measured with the Framingham Physical Activity Index ${ }^{(12)}$ during baseline testing, week 6 , and week 12.
Statistical analyses. Statistical analyses were conducted using Statistica version 7.1 (Stat Soft Inc., Tulsa, OK). Differences between groups at baseline were analyzed with independent t-tests and chisquare tests. Separate $2 \times 2$ or $2 \times 3$ (Group x Time) univariate ANOVA with repeated measures on the last factor were used to analyze between group differences over time. Since a drop-out did occur in this study, intent-to-treat analyses (ITT) were performed, using the last-observation-carried-forward method. In an ITT approach, all randomized subject's data are included in the data analyses, regardless of whether they complete the trial or are compliant with the procedures. In contrast, most studies on dietary supplements use a "per protocol" analysis and exclude non-compliant subjects or subjects who drop-out. Although a discussion of ITT analyses is beyond the scope of this paper, many researchers consider ITT to be the preferred method of data analysis in clinical efficacy studies as it is less prone to bias. Readers are referred to Hollis et al. ${ }^{(13)}$ and Moher et al. ${ }^{(14)}$ for a more thorough overview of ITT analyses. When a significant interaction was observed, Fisher's Least Significant Differences (LSD) post-hoc test was performed. When the interaction term was "marginally significant" (i.e., $0.05<\mathrm{P}<0.10$ ), changes from day 0 to day 84 within treatment groups were assessed with a paired t-test. Differences were considered statistically significant at $P<0.05$. Power analysis for this $2 \times 3$ design indicated that a sample size of 10-15 subjects per group yields moderate power $(\geq 0.80)$ for delta values of 0.75 to 1.25 .

\section{RESULTS}

Table 1 presents baseline characteristics of the subjects. Both groups met the criteria of the Adult Treatment Panel III of the National Cholesterol Education Program for having the metabolic syndrome ${ }^{(10)}$. Specifically, both groups had FBG $>$ $110 \mathrm{mg} / \mathrm{dL}$ (Cinnulin: $116 \pm 13$, Placebo: $112 \pm 10$ ), systolic BP $>130 \mathrm{~mm} \mathrm{Hg}$ (Cinnulin: $133 \pm 14$, Placebo: $133 \pm 22$ ) and triacylglycerol $>150 \mathrm{mg} / \mathrm{dL}$ (Cinnulin: $166 \pm 142$, Placebo: $165 \pm 107$ ). There were no significant differences in general, metabolic, or dietary characteristics between groups at baseline (Table 1).

Supplementation Compliance and Adverse Events. Compliance to the supplementation regimen was defined as the number of capsules actually taken by each subject divided by the number of capsules that should have been taken over the course of the study. Excluding one drop-out in the Cinnulin group, 
Table 1. Baseline Characteristics of Subjects

\begin{tabular}{|c|c|c|c|}
\hline & Placebo $(n=10)$ & Cinnulin (n=12) & P-value \\
\hline \multicolumn{4}{|l|}{ General } \\
\hline $\operatorname{Sex}(M / F)$ & $3 / 7$ & $8 / 4$ & 0.15 \\
\hline Age (y) & $45.6 \pm 11.1$ & $46.3 \pm 8.8$ & 0.88 \\
\hline Weight (kg) & $89.3 \pm 30.6$ & $93.1 \pm 18.1$ & 0.72 \\
\hline BMI $\left(\mathrm{kg} / \mathrm{m}^{2}\right)$ & $34.4 \pm 12.6$ & $32.3 \pm 5.7$ & 0.61 \\
\hline Body Fat (\%) & $43.8 \pm 8.0$ & $37.9 \pm 9.2$ & 0.13 \\
\hline Lean Mass (kg) & $43.9 \pm 11.1$ & $53.7 \pm 11.8$ & 0.06 \\
\hline \multicolumn{4}{|l|}{ Metabolic } \\
\hline Systolic Blood Pressure (mm Hg) & $133 \pm 22$ & $133 \pm 14$ & 0.94 \\
\hline Diastolic Blood Pressure (mm Hg) & $83 \pm 14$ & $83 \pm 6$ & 0.94 \\
\hline "Glucose (mg/dL) & $112 \pm 10$ & $116 \pm 13$ & 0.40 \\
\hline Total Cholesterol (mg/dL) & $192 \pm 49$ & $185 \pm 44$ & 0.72 \\
\hline LDL Cholesterol (mg/dL) & $105 \pm 52$ & $107 \pm 36$ & 0.90 \\
\hline "VLDL Cholesterol (mg/dL) & $33 \pm 21$ & $25 \pm 9$ & 0.28 \\
\hline HDL Cholesterol (mg/dL) & $55 \pm 14$ & $50 \pm 13$ & 0.36 \\
\hline Triacylglycerol (mg/dL) & $165 \pm 107$ & $166 \pm 142$ & 0.99 \\
\hline \multicolumn{4}{|l|}{ Dietary } \\
\hline Kcals/day & $1706 \pm 427$ & $1741 \pm 551$ & 0.87 \\
\hline$\%$ Carbohydrate & $46 \pm 13$ & $43 \pm 12$ & 0.59 \\
\hline "\% Fat & $33 \pm 9$ & $33 \pm 10$ & 0.98 \\
\hline$\%$ Protein & $20 \pm 11$ & $23 \pm 7$ & 0.38 \\
\hline Fiber (grams/d) & $14 \pm 7$ & $16 \pm 8$ & 0.42 \\
\hline
\end{tabular}

Data are expressed as group means $\pm \mathrm{SD}$. P-values were calculated from independent t-tests for all variables except sex (where a chi -square test was used). No significant differences were noted between groups, although there was a trend for greater lean mass in the Cinnulin group $(\mathrm{P}<0.06)$. To convert glucose from $\mathrm{mg} / \mathrm{dL}$ into $\mathrm{mmol} / \mathrm{L}$ multiply by 0.0555 ; to convert cholesterol (total, LDL-C, VLDL-C and HDL-C) from $\mathrm{mg} / \mathrm{dL}$ into $\mathrm{mmol} / \mathrm{L}$ multiply by 0.0259 ; to convert triacylglycerol from $\mathrm{mg} / \mathrm{dL}$ into $\mathrm{mmol} / \mathrm{L}$ multiply by 0.0113 .

compliance was $>97 \%$ in both groups. Adverse events were based on spontaneous reporting by subjects as well as open-ended inquiries by members of the research staff. No adverse events were reported during the study in either group.
$\boldsymbol{H R}$ and BP. After 12-weeks, subjects in the Cinnulin group decreased their SBP by $3.8 \%$ (from $133 \pm 14 \mathrm{~mm} \mathrm{Hg}$ [pre] to $128 \pm 18 \mathrm{~mm} \mathrm{Hg}$ [post], $\mathrm{P}<0.001)$ compared to subjects in the Placebo group (from $133 \pm 22 \mathrm{~mm} \mathrm{Hg}$ [pre] to $142 \pm 20 \mathrm{~mm} \mathrm{Hg}$ [post]). No between or within-group changes in diastolic blood pressure (Cinnulin: from $83 \pm 6 \mathrm{~mm}$ 
$\mathrm{Hg}$ [pre] to $84 \pm 9 \mathrm{~mm} \mathrm{Hg}$ [post]; Placebo: from $83 \pm$ $14 \mathrm{~mm} \mathrm{Hg}$ [pre] to $86 \pm 12 \mathrm{~mm} \mathrm{Hg}$ [post], $\mathrm{P}<0.32$ ) or HR (Cinnulin: from $69 \pm 14$ beats/min [pre] to $69 \pm$ 12 beats/min [post]; Placebo: from $71 \pm 15$ beats $/ \mathrm{min}$ [pre] to $74 \pm 8$ beats $/$ min [post], $\mathrm{P}<0.73$ ) were noted in either group.

Blood Chemistry. Figure 2 presents changes in FBG during the study. Subjects in the Cinnulin group had significant decreases in FBG (-8.4\%: from $116.3 \pm$ $12.8 \mathrm{mg} / \mathrm{dL}$ [pre] to $106.5 \pm 20.1 \mathrm{mg} / \mathrm{dL}$ [post], $\mathrm{P}<0.01)$ compared to subjects in the Placebo group (from $112.0 \pm 10.0 \mathrm{mg} / \mathrm{dL}$ [pre] to $113.1 \pm 14.7$ $\mathrm{mg} / \mathrm{dL}$ [post]). No other between group effects were noted for BUN, creatinine, bilirubin, alkaline phosphatase, AST (SGOT), ALT (SGPT), sodium, potassium, chloride, calcium, albumin, globulin, $\mathrm{CO}_{2}$, total protein, total cholesterol, HDL-C, LDL-C, VLDL-C, or triglycerides and all values remained within normal clinical limits (selected hematological variables are shown in Table 2).

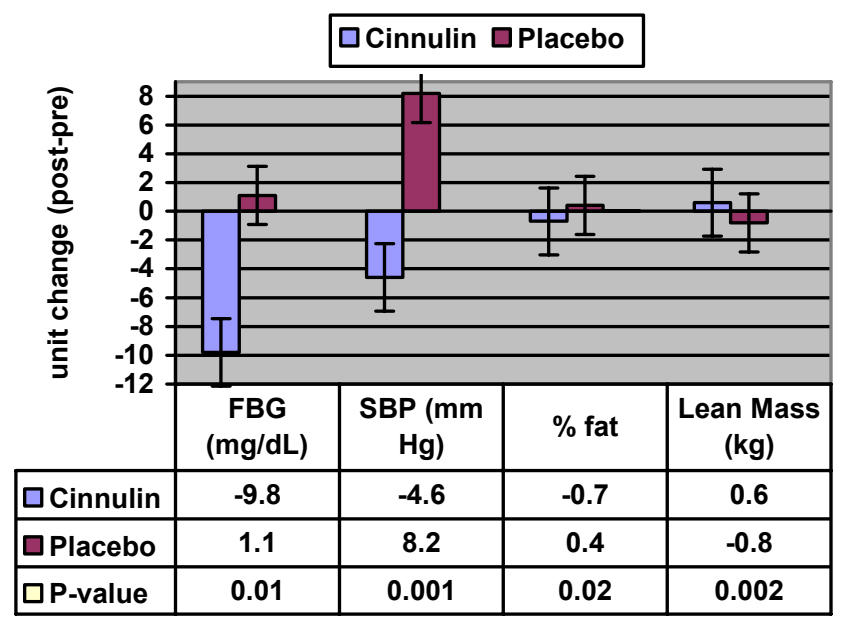

Figure 2. Significant Changes in Primary Endpoints During the Study. Data are expressed as change scores (week 12 - week 0 ). Values represent group means $\pm \mathrm{SE}$. P-values were calculated from repeated measures (group x time) ANOVA, except for $\%$ fat where a dependent $\mathrm{t}$-test was used following a marginally significant $(\mathrm{P}<0.06)$ interaction term.

Body Composition. Figure 2 presents changes in body composition during the study. Subjects in the Cinnulin group increased their lean mass by $1.1 \%$ (from $53.7 \pm 11.8 \mathrm{~kg}$ [pre] to $54.3 \pm 11.8 \mathrm{~kg}$ [post], $\mathrm{P}<0.002$ ), and decreased their body fat by $0.7 \%$ (from $37.9 \pm 9.2 \%$ [pre] to $37.2 \pm 8.9 \%$ [post]; within-group analysis, $\mathrm{P}<0.02$ ). No changes in lean mass (from $43.9 \pm 11.1 \mathrm{~kg}$ [pre] to $43.1 \pm 10.9 \mathrm{~kg}$ [post]) or fat mass (from $43.8 \pm 8.0 \%$ [pre] to $44.2 \pm 9.0 \%$ [post]) were noted in the Placebo group. Because the baseline value for lean mass was marginally significant $(\mathrm{P}<0.06)$, we also performed an ANCOVA using week 0 lean mass as the covariate. Results confirmed that lean mass at week-12 was significantly greater in the Cinnulin group $(\mathrm{P}<0.004)$.

Diet and Physical Activity. Table 3 presents totals for three-day dietary intake obtained during the study. No changes in total daily energy, macronutrient, or fluid intake were noted during the study, although there was a trend for subjects in the Cinnulin group to consume more total energy $(\mathrm{P}<0.07)$. Follow-up testing for within-group changes (via dependent t-test) indicated subjects in the Cinnulin group ingested significantly more total energy during week-12 $(\mathrm{P}<0.04)$. Due to errors in data recording and processing, our quantitative assessment of physical activity (via the Framingham Physical Activity Index) could not be accurately completed. However, during mid and post-testing, no subject reported any changes in habitual activity levels during the course of the study.

\section{DISCUSSION}

Our findings indicate that consuming $500 \mathrm{mg} /$ day of a specific aqueous extract of cinnamon (Cinnulin $\mathrm{PF}$ ) for 12-weeks leads to significant improvements in several features of the metabolic syndrome (i.e., fasting blood sugar, systolic blood pressure, and body composition). Because of the relationship between the metabolic syndrome and cardiovascular disease, these results, if confirmed by other research groups, have important implications for public health. To our knowledge, this is the first study in humans that used cinnamon powder standardized to what is currently considered to be the bioactive component (e.g. doubly-linked polyphenol type-A polymers) ${ }^{2}$. This is important as Cinnamomum cassia is a large genus, and there may be differences in bioactivity due to methods of preparation, extraction, and geographical source.

The observed reduction in FBG in our study is less than that of Khan et al. ${ }^{6}$ and similar in magnitude to Mang et al. ${ }^{7}$. Khan et al. studied the effects of 1,3, and $6 \mathrm{~g} / \mathrm{d}$ of whole cinnamon powder on FBG and serum lipids in 60 people with poorly controlled type 2 diabetes from Pakistan. After 40 days of supplementation, FBG decreased by $18-29 \%$, cholesterol decreased by 12-26\%, LDL cholesterol decreased by $7-27 \%$, and triacylglycerol decreased by 23-30\%. More recently, Mang et al. supplemented 79 people with type 2 diabetes from Germany with $3 \mathrm{~g} / \mathrm{d}$ cinnamon powder or a placebo for four months. 
Table 2. Selected Hematological Responses to Supplementation.

\begin{tabular}{|l|c|c|c|c|}
\hline & $\begin{array}{c}\text { Placebo } \\
\text { (n=10) }\end{array}$ & $\begin{array}{c}\text { Cinnulin } \\
(\mathbf{n}=12)\end{array}$ & $\begin{array}{c}\text { P-value } \\
\text { (GxT) }\end{array}$ & $\begin{array}{c}\text { Reference } \\
\text { Interval }\end{array}$ \\
\hline BUN:Creatinine & $16 \pm 5$ & $16 \pm 4$ & 0.21 & $8-27$ \\
\hline Pre & $19 \pm 5$ & $18 \pm 4$ & & \\
\hline Mid & $16 \pm 4$ & $18 \pm 4$ & & \\
\hline Post & & & 0.50 & $0.1-1.2$ \\
\hline Bilirubin (mg/dL) & $0.5 \pm 0.1$ & $0.7 \pm 0.3$ & & \\
\hline Pre & $0.5 \pm 0.1$ & $0.8 \pm 0.4$ & & \\
\hline Mid & $0.5 \pm 0.2$ & $0.6 \pm 0.3$ & & \\
\hline Post & & & 0.12 & $25-150$ \\
\hline $\begin{array}{l}\text { Alkaline Phosphatase } \\
\text { (IU/L) }\end{array}$ & $77 \pm 17$ & $65 \pm 14$ & & \\
\hline Pre & $71 \pm 16$ & $67 \pm 16$ & & \\
\hline Mid & $67 \pm 16$ & $60 \pm 11$ & & \\
\hline Post & & & 0.94 & $0-40$ \\
\hline $\begin{array}{l}\text { Aspartate } \\
\text { aminotransferase (IU/L) }\end{array}$ & $29 \pm 15$ & $29 \pm 17$ & & \\
\hline Pre & $26 \pm 11$ & $26 \pm 13$ & & \\
\hline Mid & $25 \pm 8$ & $24 \pm 8$ & & \\
\hline Post & & & 0.59 & $0-40$ \\
\hline $\begin{array}{l}\text { Alanine } \\
\text { aminotransferase (IU/L) }\end{array}$ & $30 \pm 16$ & $38 \pm 28$ & & \\
\hline Pre & $30 \pm 17$ & $34 \pm 25$ & & \\
\hline Mid & $28 \pm 14$ & $32 \pm 22$ & & \\
\hline Post & & & 0.81 & $100-199$ \\
\hline Cholesterol (mg/dL) & $192 \pm 49$ & $185 \pm 44$ & & \\
\hline Pre & $191 \pm 50$ & $190 \pm 36$ & & \\
\hline Mid & $193 \pm 47$ & $190 \pm 33$ & & \\
\hline Post & $105 \pm 52$ & $107 \pm 36$ & & \\
\hline Triacylglycerol (mg/dL) & $165 \pm 107$ & $166 \pm 142$ & & \\
\hline Pre & $172 \pm 111$ & $152 \pm 76$ & & \\
\hline Mid & $195 \pm 146$ & $162 \pm 132$ & & \\
\hline Post & $55 \pm 14$ & $50 \pm 13$ & & \\
\hline HDL (mg/dL) & $54 \pm 15$ & $48 \pm 13$ & & \\
\hline Pre & $55 \pm 16$ & $50 \pm 13$ & & \\
\hline Mid & $33 \pm 21$ & $25 \pm 9$ & & \\
\hline Post & $34 \pm 21$ & $30 \pm 15$ & & \\
\hline VLDL (mg/dL) & $36 \pm 22$ & $25 \pm 11$ & & \\
\hline Pre & & $111 \pm 29$ & & \\
\hline Mid & & & & \\
\hline Post & & & \\
\hline LDL (mg/dL) & & & \\
\hline Pre & & & \\
\hline Mid & & & \\
\hline Post & & & \\
\hline
\end{tabular}

Data are expressed as group means $\pm \mathrm{SD}$. P-values were calculated from two-way (group $\mathrm{x}$ time) ANOVA. No significant differences were noted between groups over time. To convert bilirubin from $\mathrm{mg} / \mathrm{dL}$ into $\mathrm{mmol} / \mathrm{L}$ multiply by 17.1 ; to convert cholesterol (total, LDL-C, VLDL-C and HDL-C) from $\mathrm{mg} / \mathrm{dL}$ into $\mathrm{mmol} / \mathrm{L}$ multiply by 0.0259 ; to convert triacylglycerol from $\mathrm{mg} / \mathrm{dL}$ into $\mathrm{mmol} / \mathrm{L}$ multiply by 0.0113 .

Although no changes in blood lipids or glycosylated hemoglobin $\left(\mathrm{HBA}_{1 \mathrm{c}}\right)$ were noted, researchers did find a $10.3 \%$ reduction in FBG. In both studies (as well as ours), no adverse events were reported by subjects taking cinnamon, and subjects with the poorest glycemic control appeared to benefit the most. In agreement with Mang et al. ${ }^{7}$, but in contrast to Khan et al. ${ }^{6}$, we found no changes in blood lipids from cinnamon supplementation. We suspect this is because: 1) our subjects' lipid levels were not 
abnormal, and 2) the observed decrease in FBG ($8.4 \%$ ) was not large enough to affect lipid metabolism. Regardless, given the strong effects of cinnamon on insulin signaling in animal models, future studies in humans should consider examining changes in more sensitive predictors of cardiovascular disease risk (i.e., various lipoprotein subfractions). The statistically significant decrease in systolic SBP observed in this study (from 133 to 129 $\mathrm{mm} \mathrm{Hg}, \mathrm{P}<0.001$ ) echoes findings from Preuss et al. 11 in spontaneously hypertensive rats, and was clinically meaningful in that values $>130 \mathrm{~mm} \mathrm{Hg}$ are considered to be a risk factor for the metabolic syndrome ${ }^{10}$.

Not all studies have found beneficial effects of cinnamon on FBG. Vanschoonbeek et al. ${ }^{15}$ reported no effect of $1.5 \mathrm{~g} / \mathrm{d} \times 6 \mathrm{wk}$ cinnamon powder on indices of glycemic control (FBG, insulin, oral glucose tolerance test [OGTT], $\mathrm{HBA}_{1 \mathrm{c}}$, insulin sensitivity, and insulin resistance) or blood lipids in 25 postmenopausal women from the Netherlands. That study is different from that of Khan et al. ${ }^{6}$ and Mang et al. ${ }^{7}$ (as well as the current study) in that only postmenopausal females were included as subjects. Whether differences in hormonal milieu affect the potential interaction between cinnamon supplementation and glucose control is unknown at this time.

A unique finding in our study is the small, but statistically significant improvement in body composition from Cinnulin $\mathrm{PF}{ }^{\circledR}$ supplementation. Previous research has shown cinnamon extracts can activate glycogen synthase, stimulate glucose uptake, and inhibit glycogen synthase kinase $3 \beta^{1-3,16}$. Collectively, these effects, combined with the slight increase in total energy intake, may have led to the observed increases in lean mass in the Cinnulin PF ${ }^{\circledR}$ group. Cinnamon also has antioxidant effects ${ }^{17-19}$ that may favorably impact hormone signaling via adipokine cross-talk. For example, Chrysohoou et al. ${ }^{19}$ recently reported an inverse relationship between body fat and antioxidant capacity, even after controlling for smoking, physical activity patterns, dietary habits, blood pressure, glucose levels, and lipid concentrations. It is therefore possible that the observed improvements in FBG, as well as plasma antioxidant status (e.g., FRAP, MDA, and $\mathrm{SH}-$ manuscript in preparation) are responsible, at least in part, for cinnamon's beneficial effects on body composition and features of the metabolic syndrome.

Summary. In many parts of the civilized world, physical inactivity and poor dietary habits are increasing rates of prediabetes, obesity, and the development of cardiovascular diseases. Current estimates are that the metabolic syndrome affects over $26 \%$ of adults, or over 50 million Americans, and that it increases the risk for atherosclerotic cardiovascular disease up to 3 -fold, and the risk for type 2 diabetes up to 5 -fold ${ }^{(9)}$. Based on the results of this study, Cinnulin $P F ®$ may play a beneficial role in ameliorating the effects of several chronic diseases of modernization. Although speculative, because subjects in this study were not required to follow any specific diet or exercise program, it is possible that combining Cinnulin $\mathrm{PF}{ }^{\circledR}$ with a nutrient-dense diet and/or a regular exercise program may lead to even greater health benefits. These preliminary data support the efficacy of Cinnulin $P F \circledR$ supplementation on reducing FBG in prediabetic men and women. It also appears that this particular watersoluble cinnamon extract, standardized for polyphenolic type-A polymers, can favorably alter systolic blood pressure and body composition when consumed for at least 12-weeks. Finally, although it is acknowledged that we used a relatively small, homogeneous sample of subjects, Cinnulin PF® appears to be reasonably safe at the dose and duration studied. Larger, longer-term multi-center studies are necessary to confirm our findings, determine the mechanism(s) underpinning the observed physiological effects, and delineate any doseresponse effects from this naturally-occurring spice.

Table 3. Three-day Total Dietary Intake of Subjects

\begin{tabular}{|c|c|c||c||c||c|}
\hline & $\begin{array}{c}\text { Placebo } \\
\text { (pre) }\end{array}$ & $\begin{array}{c}\text { Placebo } \\
\text { (post) }\end{array}$ & $\begin{array}{c}\text { Cinnulin } \\
\text { (pre) }\end{array}$ & $\begin{array}{c}\text { Cinnulin } \\
\text { (post) }\end{array}$ & $\begin{array}{c}\text { P-value } \\
\text { (GxT) }\end{array}$ \\
\hline $\begin{array}{c}\text { Total energy } \\
\text { (kcals/d) }\end{array}$ & $\begin{array}{c}1706 \pm \\
427\end{array}$ & $\begin{array}{c}1613 \pm \\
364\end{array}$ & $\begin{array}{c}1741 \pm \\
551\end{array}$ & $\begin{array}{c}1982 \pm \\
530\end{array}$ & 0.07 \\
\hline $\begin{array}{c}\text { Carbohydrate } \\
(\%)\end{array}$ & $46 \pm 13$ & $46 \pm 11$ & $43 \pm 12$ & $43 \pm 10$ & 0.94 \\
\hline Fat (\%) & $33 \pm 9$ & $33 \pm 8$ & $33 \pm 10$ & $35 \pm 7$ & 0.70 \\
\hline Protein (\%) & $20 \pm 11$ & $20 \pm 7$ & $23 \pm 7$ & $21 \pm 7$ & 0.91 \\
\hline Fluid Intake (oz) & $20 \pm 10$ & $25 \pm 8$ & $24 \pm 9$ & $25 \pm 9$ & 0.39 \\
\hline $\begin{array}{c}\text { Saturated fat } \\
\text { (g/d) }\end{array}$ & $18 \pm 10$ & $18 \pm 11$ & $16 \pm 7$ & $23 \pm 13$ & 0.37 \\
\hline $\begin{array}{c}\text { Cholesterol } \\
\text { (mg/d) }\end{array}$ & $331 \pm 239$ & $280 \pm 174$ & $258 \pm$ & $275 \pm$ \\
137 & 0.26 \\
\hline $\begin{array}{c}\text { Sodium (mg/d) } \\
\text { (monn }\end{array}$ & $3402 \pm$ & $4160 \pm$ & $4426 \pm$ \\
2351 & $\begin{array}{c}4419 \pm \\
1943\end{array}$ & 0.58 \\
\hline Fiber (g/d) & $14 \pm 7$ & $17 \pm 7$ & $16 \pm 8$ & $20 \pm 11$ & 0.65 \\
\hline
\end{tabular}

Data are expressed as group means $\pm \mathrm{SD}$. P-values were calculated from repeated measures (group $\mathrm{x}$ time) ANOVA. No significant differences were noted between groups over time, although there was a trend $(\mathrm{P}<0.07)$ for subjects in the Cinnulin group to ingest more total energy. To convert from kcals into Joules (kJ) multiply by 4186; to convert from ounces (oz) into milliliters multiply by 29.573 . 


\section{ACKNOWLEDGEMENTS AND DISCLOSURE}

We would like to thank the dedicated group of subjects who participated in this study. This research was sponsored by a grant from Integrity Nutraceuticals International (Sarasota, FL). The presentation of results of this study does not constitute endorsement by any of the researchers or their affiliations. Integrity Nutraceuticals International had no role in the collection, analyses, or interpretation of the data.

TZ, JH, RM, and RA contributed to the design of the study. JH carried out the practical aspects of the study, including data collection and dietary analyses. $\mathrm{TZ}$ and RM performed the statistical analyses. TZ wrote the first draft of the manuscript with help from RA and JL. All authors participated in editing the final draft of the manuscript. At the time of data collection and analysis, as well as initial submission of the manuscript for publication, none of the authors had any conflicts of interest. TZ served as a consultant to Integrity Nutraceuticals International from 10/2005 to 10/2006 and Richard Anderson has a USDA Cooperative Research and Development Agreement with Integrity Nutraceuticals.

\section{REFERENCES}

1. Broadhurst CL, Polansky MM, Anderson RA. Insulin-like biological activity of culinary and medicinal plant extracts in vitro. $J$ Agric Food Chem. 2000 Mar;48(3):849-852.

2. Anderson RA, Broadhurst CL, Polansky MM, et al. Isolation and characterization of polyphenol type-A polymers from cinnamon with insulin-like biological activity. Agric Food Chem. 2004 Jan;52(1):65-70.

3. Jarvill-Taylor KJ, Anderson RA, Graves DJ. A hydroxychalcone derived from cinnamon functions as a mimetic for insulin in 3T3-L1 adipocytes. J Am Coll Nutr. 2001 20:327-336.

4. Qin B, Nagasaki M, Ren M, et al. Cinnamon extract (traditional herb) potentiates in vivo insulin-regulated glucose utilization via enhancing insulin signaling in rats. Diabetes Res Clin Pract. 2003 62:139-148.

5. Qin B, Nagasaki M, Ren M, et al. Cinnamon extract prevents the insulin resistance induced by a high-fructose diet. Horm Metab Res. $2004 \mathrm{Feb}$;36(2):119-125.

6. Khan A, Safdar M, Ali Khan MM, et al. Cinnamon improves glucose and lipids of people with type 2 diabetes. Diabetes Care. 2003 Dec;26(12):3215-3218.

7. Mang B, Wolters M, Schmitt B, et al. Effects of a cinnamon extract on plasma glucose, HbA1c, and serum lipids in diabetes mellitus type 2. Eur J Clin Investig. 2006 36:340-344.

8. Davidson MB. Clinical implications of insulin resistance syndrome. Am J Med. 1995 99:420-426.

9. Borgman M, McErlean E. What is the metabolic syndrome? Prediabetes and cardiovascular risk. J Cardiovasc Nurs. 2006 JulAug;21(4):285-290.

10. Expert Panel on Detection, Evaluation, and Treatment of High Blood Cholesterol in Adults: Executive summary of the third report of the National Cholesterol Education Program (NCEP) Exert Panel on Detection, Evaluation, and Treatment of High Blood Cholesterol in Adults (Adult Treatment Panel III). JAMA. 2001 285:2486-2497.

11. Preuss HG, Echard B, Polansky MM, Anderson R. Whole cinnamon and aqueous extracts ameliorate sucrose-induced blood pressure elevations in spontaneously hypertensive rats. J Am Coll Nutr. 2006 Apr;25(2):144-150.

12. Kannel WB, Sorlie P. Some health benefits of physical activity: The Framingham Heart Study. Arch Intern Med. 1979 139:857861.

13. Hollis S, Campbell F. What is meant by intention to treat analysis? Survey of published randomized controlled trials. BMJ. 1999 319:670-674.

14. Moher D, Schulz KF, Altman DG, et al. The CONSORT statement: revised recommendations for improving the quality of reports of parallel-group randomised trials. Clin Oral Investig. 2003 Mar;7(1):2-7.

15. Vanschoonbeek K, Thomassen B, Senden J, et al. Cinnamon supplementation does not improve glycemic control on postmenopausal type 2 diabetes patients. J Nutr. 2006 136:977-980.

16. Imparl-Radosevich J, Deas S, Polansky MM, et al. Regulation of PTP-1 and insulin receptor kinase by fractions from cinnamon: implications for cinnamon regulation of insulin signaling. Horm Res. 1998 50:177-182.

17. Shan B, Cai YZ, Sun M, Corke H. Antioxidant capacity of 26 spice extracts and characterization of their phenolic constituents. $J$ Agric Food Chem. 2005 Oct 5;53(20):7749-7759.

18. Blomhoff R. Antioxidants and oxidative stress (Review). Tidsskr Nor Laegeforen. 2004 Jun 17;124(12):1643-1645.

19. Chrysohoou C, Panagiotakos DB, Pitsavos C, et al. The implication of obesity on total antioxidant capacity in apparently healthy men and women: The ATTICA study. Nutr Metab Cardiovasc Dis. 2006 Aug 8; [Epub ahead of print]. 